\title{
A Utilização do Software Wiris na Plataforma Moodle Visando o Ensino da Matemática: o Relato de um Projeto de Extensão
}

\author{
Jaqueline Zdebski da Silva Cruz - Unioeste - jaque_zdebski@ hotmail.com \\ Amarildo de Vicente - Unioeste - amarildo.vicente@ gmail.com \\ André Luiz Brun - Unioeste - andrebrun@ hotmail.com \\ Claudia Brandelero Rizzi - Unioeste - claudia_rizzi@hotmail.com \\ Rogério Luís Rizzi - Unioeste - rogeriorizzi@ hotmail.com
}

\begin{abstract}
Resumo. Este artigo apresenta alguns resultados obtidos pela realização de um projeto de extensão universitária que foi realizado no município de Catanduvas - Paraná, cujo principal objetivo era o de articular a Matemática e a Informática visando contribuir para a melhoria das condições de cidadania, emprego, renda e acesso às instituições de ensino superior, por parte de alunos que cursavam o ensino médio. Relata a utilização do software Wiris Editor utilizado em um curso disponibilizado no ambiente Moodle criado para atender os alunos do projeto.
\end{abstract}

Palavras chaves: ensino de matemática, informática e educação, Moodle, Wiris.

Abstract. This article presents some results from the execution of an extension's project conducted at Catanduvas - Paraná, whose main goal was to articulate the Mathematics and Computer Science to contribute to the improvement of conditions for citizenship, employment, income and access to institutions of higher education by students who attended high school. We report the use of software Wiris Editor used in a course available in Moodle designed to meet the students of the project.

Keywords: teaching of mathematics, informatics and education, Moodle, Wiris.

\section{Introdução}

Devido às diversas dificuldades encontradas no processo de ensino-aprendizagem da matemática, as discussões envolvendo seu ensino vêm se intensificando, em particular, no campo da Educação Matemática, onde novas metodologias estão sendo estudadas e propostas como reais possibilidades de melhoria.

Uma destas possibilidades é o uso da informática no ensino da matemática. $\mathrm{O}$ constante desenvolvimento de softwares educacionais e a popularização do uso do computador permitem que escolas e professores possam cada vez mais apoiar-se na interação aluno/computador como possibilidade de originar conhecimentos. Segundo Valente, as tecnologias contribuem para o desenvolvimento de uma aprendizagem significativa, prazerosa e eficaz, capaz de despertar no educando, o interesse e a motivação pela busca do conhecimento (Valente, 2008).

O presente trabalho apresenta alguns resultados obtidos através do uso da informática no desenvolvimento das atividades previstas no âmbito do projeto de extensão intitulado "Uma Articulação entre a Matemática e a Informática como Instrumento para a Cidadania e o Emprego, e acessibilidade às IES", também chamado de Projeto USFMat. A abordagem metodológica adotada visou tentar qualificar o estudante para suas necessidades básicas de informática, para o mercado de trabalho e também para utilizar os recursos computacionais que foram empregados como mediadores nas aulas de matemática oferecidas, apoiadas pela internet. 
Este trabalho apresenta a seguinte organização: a seção dois mostra algumas características do projeto de extensão cujos autores foram colaboradores e que é tomado para fundamentar as discussões realizadas. A terceira seção apresenta uma discussão sobre o uso da informática no ensino da matemática. No desenvolver da quarta seção faz-se algumas considerações e discussões a respeito da utilização do Moodle e do Wiris no projeto USFMat. Por fim, a seção cinco apresenta comentários finais deste trabalho.

\section{O projeto USFMat}

Em 2009 se propôs, foi aprovado e teve início o projeto de extensão USFMat na Universidade Estadual do Oeste do Paraná (Unioeste). Este projeto foi financiado pela Secretaria de Estado da Ciência, Tecnologia e Ensino Superior (SETI), através do Programa Universidade Sem Fronteiras (USF), que em 2010 foi considerado o maior programa de extensão universitária em desenvolvimento no Brasil (USF, 2010). Dele fizeram parte professores dos colegiados de matemática e de ciência da computação, desta mesma Universidade. Também colaboraram alunos de graduação destes dois cursos e uma professora de matemática recém-formada.

A proposta principal do Projeto de Extensão USFMat, foi levar aos alunos do ensino médio do município de Catanduvas, no estado do Paraná, conhecimentos nas áreas de matemática e informática, buscando oferecer a eles a oportunidade de capacitação nestas duas áreas, que se concebe, são importantes tanto na formação do cidadão e do vestibulando quanto para o competitivo mercado de trabalho no qual eles estão sendo inseridos.

Catanduvas é uma pequena cidade do oeste do Paraná e está localizada a cerca de $50 \mathrm{Km}$ da cidade de Cascavel, campus da Unioeste ao qual os colaboradores do USFMat estão vinculados. Possui aproximadamente 9600 habitantes e faz parte de um grupo constituído por 20 municípios chamado de território do Cantuquiriguaçu, que é considerada a região mais pobre do estado. Segundo o Diagnóstico Socioeconômico do Território Cantuquiriguaçu, a renda é o que mais compromete o desempenho da cidade de Catanduvas em seu Índice de Desenvolvimento Humano-Municipal (IDH-M), assim como acontece também com outras cidades dessa região, fazendo com que esses municípios ocupem posições bastante desfavoráveis no ranking estadual, apresentando índices próximos do limite extremo. Catanduvas ocupa a 275. ${ }^{\mathrm{a}}$ posição no ranking dos 399 municípios paranaenses em termos de desenvolvimento (Ipardes, 2007).

Os alunos de Catanduvas participantes deste projeto, assim como acontece também em outras pequenas localidades, procuram ingressar em Instituições de Ensino Superior (IES), inexistentes no município, mas também permanecem trabalhando na própria cidade. Do público específico participante deste projeto aproximadamente $30 \%$ já desempenha alguma atividade no mercado de trabalho de Catanduvas e cerca de $70 \%$ dos alunos concluintes pretendem prestar vestibular em 2010. Daí a motivação e justificativa em se incluir no projeto atividades que contribuam tanto para o acesso às IES quanto para a capacitação visando emprego e renda. E para que isso pudesse acontecer de forma conjunta a proposta do projeto foi a de articular a Matemática e a Informática.

A realização do projeto foi dividida basicamente em três partes: as aulas de matemática e de micro-informática realizadas aos sábados na escola, e o uso da informática como ferramenta de ligação entre as partes envolvidas proporcionando a interação dos mesmos nos momentos de monitoria, realizados durante a semana, através 
de chats, fóruns e avaliações que eram realizadas online via Moodle.

Os conteúdos matemáticos foram apresentados aos alunos de uma forma diferenciada, já que todos os tópicos abordados foram desenvolvidos com base na resolução de problemas voltados a realidade do aluno e no uso da informática, o que permite uma melhor compreensão da aplicabilidade da mesma.

Apesar de oferecer disciplinas como álgebra, geometria e trigonometria, o enfoque principal da matemática no decorrer do projeto esteve voltado a dois tópicos específicos: Matemática Comercial e Matemática Financeira. Esses dois tópicos foram apresentados com o objetivo de capacitar o aluno para o mercado de trabalho possibilitando melhorias nas condições de emprego e renda e foram trabalhados articuladamente com a computação, de maneira que os conteúdos abordados em sala de aula através da apresentação de situações cotidianas, eram revistos no laboratório de informática e trabalhados com os recursos que esta oferece.

\section{Utilização da informática no ensino de matemática}

Não é de hoje que são estudadas as causas das dificuldades encontradas pelos alunos na compreensão dos conteúdos matemáticos, independentemente do nível de formação, desde a educação infantil e até os cursos de graduação. A crescente preocupação com as dificuldades e com a exclusão educacional que elas causam, resultou no aumento das pesquisas em novas metodologias e recursos que possam ampliar as possibilidades de aprendizagem por parte dos alunos. Uma destas propostas consiste em usar a informática como meio, como ferramenta de complementação, aperfeiçoamento e de possível mudança na qualidade do ensino da matemática.

O aprender com a tecnologia, considera que o aluno é um sujeito ativo, elemento fundamental no processo de ensino e aprendizagem. A aprendizagem com tecnologia pode estar baseada nas teorias construtivistas, nas quais o conhecimento é construído pelo sujeito e não transmitido. Desta forma, a presença do computador deve propiciar as condições para os estudantes exercitarem a capacidade de procurar e selecionar informação, resolver problemas e aprender independentemente (Valente, 1993), atitudes essenciais que devem ser desenvolvidas na formação matemática do aluno.

Atualmente, a informática está sendo usada na educação como apoio à aprendizagem nos cursos presenciais ou semi presenciais que estão incluídos na modalidade de ensino conhecida como Educação à Distância (EAD), como é o caso do projeto em discussão, que ofereceu aulas presenciais semanais e utilizou a informática como apoio as aulas nos momentos intermediários as datas das mesmas. Nesta modalidade, a mediação didático-pedagógica nos processos de ensino e aprendizagem ocorre com a utilização de meios e Tecnologias de Informação e Comunicação (TICs) onde os estudantes e professores desenvolvem atividades educativas em lugares e horários diferenciados.

Belloni (1998) afirma que a EAD emerge no contexto das sociedades contemporâneas para atender às novas mudanças sociais e educacionais, decorrentes da nova ordem econômica mundial. O desafio da EAD, no contexto atual, é, sobretudo, oferecer um sistema de ensino aberto e eficaz que facilite a seleção e apropriação da informação e do conhecimento, reduzindo as barreiras da distância e do tempo real, sem perder de vista os fins educacionais a que se propõe.

Um exemplo já tradicional do uso das TICs em EAD é sua viabilização através 
do uso do sistema gerenciador de cursos Moodle, que foi utilizado pelo projeto USFMat e é apresentado na próxima seção. Trata-se de uma ferramenta interessante no sentido de auxiliar o aprendizado da matemática, já que através dele o aluno pode, a qualquer hora, buscar conhecimentos extras e sanar dúvidas remanescentes, a qualquer tempo e lugar, desde que viabilizado o aceso à internet (Gonçalves, Salvador, 2002).

\subsection{Moodle}

O Moodle (Modular Object Oriented Distance Learning Environment) é um sistema de administração de atividades educacionais que viabiliza a criação e gestão de cursos online. Pode ser utilizado nos diversos níveis de ensino e de várias formas, desde a mais simples, que seria a disponibilização de materiais na plataforma até as mais elaboradas nas quais os alunos desenvolvem e enviam trabalhos através das ferramentas disponibilizadas no sistema. É utilizado em Instituições Públicas de Ensino Superior onde é adotado como um dos principais meios de acesso ao ensino à distância.

Algumas características do Moodle que justificam sua ampla utilização: trata-se de um software gratuito, que já possui uma grande comunidade de desenvolvedores em todo mundo; possui interface completa e de fácil compreensão pelos alunos; sistema de chats e fóruns, amplamente utilizados como tira-dúvidas; proporciona recursos de interação como chat, fórum, mensagens, workshop, wiki, etc; oferece suporte tecnológico para a disponibilização de conteúdos de acordo com um modelo pedagógico e design instrucional; permite a realização de avaliações de alunos, controle de acessos, atribuição de notas; possui ferramenta de autoria própria já embutida além de apresentar vários tipos de questionários e lições.

Essas funcionalidades aliadas aos plugins que podem ser a ele adicionados, fazem do Moodle um ambiente virtual de aprendizagem muito utilizado para gerenciar cursos das mais diversas áreas do conhecimento, nas modalidades totalmente à distância, semi-presenciais e também como apoio para cursos presenciais.

Este sistema permite integrar recursos que facilitam o ensino da matemática em qualquer página da plataforma, como nas lições, textos, chats, fóruns e realização de tarefas on-line. Ele disponibiliza vários recursos que facilitam a escrita e a comunicação de objetos matemáticos entre seus usuários, o que significa que no texto, esteja ele em fóruns, enunciados de tarefas ou durante as conversas nos chats, os professores e alunos dispõem da opção de escrever textos com fórmulas e símbolos matemáticos de maneira rápida e fácil. Um destes recursos é o aplicativo Wiris Editor que foi utilizado no desenvolver de algumas atividades on-line, via Moodle, envolvendo a matemática no projeto USFMat. Apresenta-se a seguir, algumas características deste aplicativo.

\subsection{Wiris}

O aplicativo Wiris Editor, exibido na figura 1, é uma ferramenta que tem como principal função editar fórmulas e resolver cálculos. Ele disponibiliza também outras funções como a possibilidade de trabalho com sistemas de equações, geometria plana e espacial, aritmética, combinatória, estatística, cálculo, etc, dentro do ambiente Moodle. O software foi desenvolvido especificamente para a educação e é utilizado em diversos países por alunos e professores, especialmente das ciências exatas (Tortosa, 2004). 


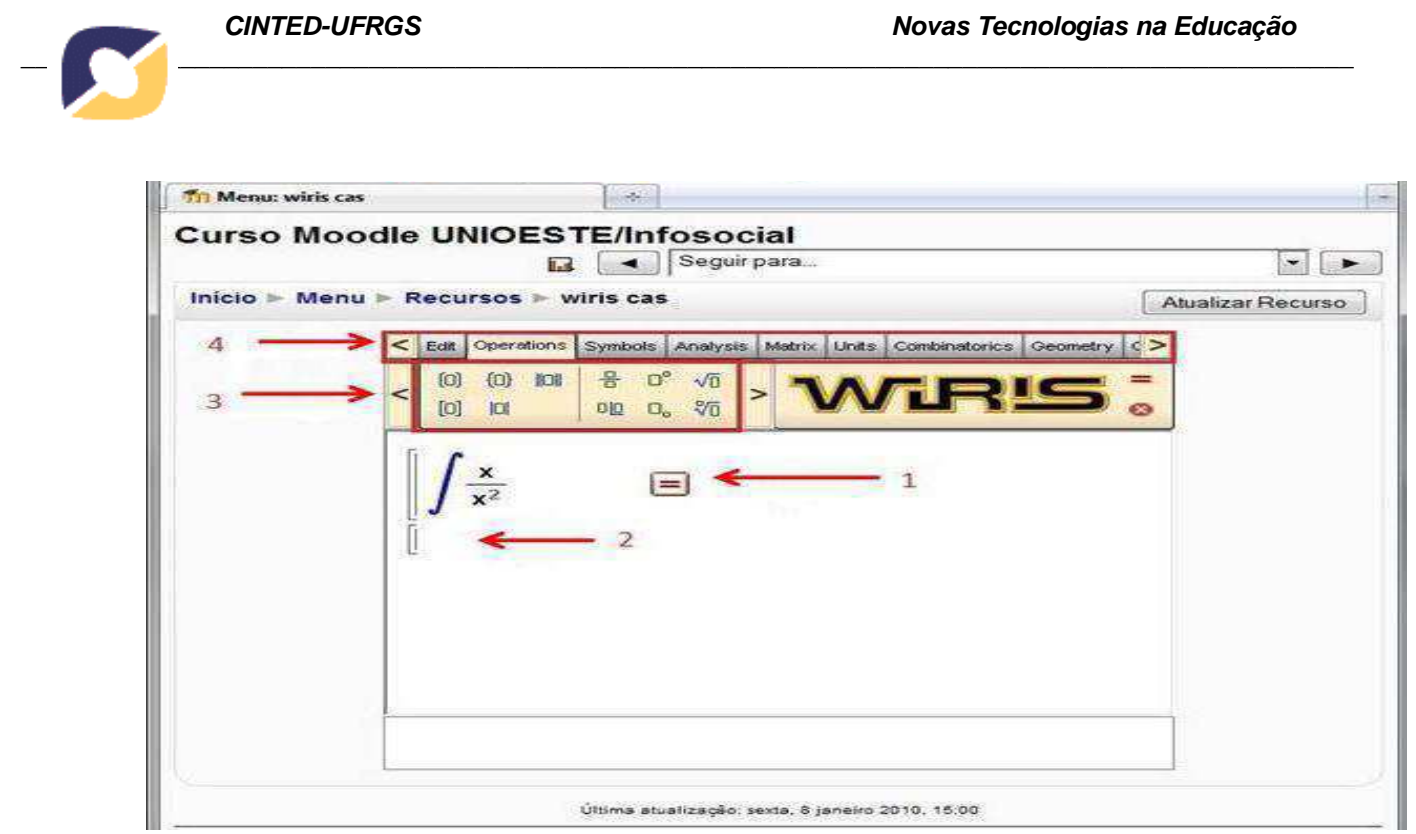

Figura 1 - A interface do software Wiris Editor dentro do ambiente Moodle

O Wiris também possui outros tipos de recursos, como por exemplo, a detecção de erros, que podem ser de sintaxe ou de digitação. Erros de sintaxe tratam elementos que faltam para as operações, como por exemplo parênteses abertos ou o uso de símbolos não existentes. Já nos casos de erros de digitação são apontadas, por exemplo, expressões matemáticas que não têm sentido lógico. Recursos como estes fazem com que o uso do software seja menos unilateral, uma vez que o usuário recebe um feedback, mostrando o porquê de seu cálculo não estar correto (Marques, 2006).

Esta capacidade de disponibilizar tarefas visuais e interativas possibilitada pelo Wiris contribui para promover situações de maior motivação para a realização dos trabalhos e torna as tarefas mais eficientes do ponto de vista educacional, uma vez que o aluno tem maior contato com o conteúdo, já que ele visualiza seu trabalho em um ambiente onde existem representações e figuras. O Wiris Editor não é uma ferramenta estática e sim um software capaz de interagir com o aluno enquanto o informa onde e de que natureza são os possíveis erros cometidos contribuindo para o processo ensinoaprendizagem de forma positiva, pois incentiva o aluno na criação de soluções próprias (Xambó, Eixarch, 2002).

Cabe dizer que o Wiris não é o único software de edição matemática que pode ser usado no Moodle: outro exemplo é o DragMath. Apesar das semelhanças existentes entre estes dois softwares a escolha pelo uso do aplicativo Wiris Editor no projeto USFMat se deu tendo em vista as possibilidades que ele oferece e possibilitou para a equipe desenvolver e disponibilizar aos alunos uma gama extensa de exercícios e trabalhos de matemática, principalmente aquelas atividades que envolvem as geometrias plana e espacial e sua visualização gráfica. Planejou-se não apenas as antigas e conhecidas listas de exercícios, mas também tarefas interativas nas quais o aluno desenvolve através de uma atividade investigativa, formas de resolução próprias com a ajuda dos recursos que o aplicativo oferece, como por exemplo, a construção de gráficos e de figuras em duas ou três dimensões. Algumas destas situações são relatadas a seguir.

\section{Considerações sobre a utilização do Moodle e do Wiris}

No âmbito do projeto USFMat, o Moodle foi utilizado pelos alunos em várias situações: durante as aulas presenciais no desenvolvimento de algumas atividades investigativas 
com o uso do Wiris; nas consultas extra-aula onde os alunos tinham acesso à materiais adicionais dos cursos ministrados; nos momentos onde os alunos desenvolveram as atividades propostas às quais foram submetidas a avaliações e atribuídas notas e na busca por ajuda quando os alunos postavam questionamentos nos fóruns e participavam das discussões nos chats onde tinham oportunidade de tirar dúvidas e adquirir conhecimentos além daqueles oferecidos em sala de aula, em tempo real, com a ajuda dos monitores.

Apesar dos alunos envolvidos no projeto terem recebido treinamento para a utilização dos recursos em questão, observamos que o Moodle foi utilizado por eles com pouca freqüência, ou pelo menos com uma freqüência menor do que aquela que esperávamos. Isso talvez possa ser atribuído à falta de costume dos alunos de se utilizarem da internet para revisar os conteúdos vistos na sala de aula e para buscarem novos conhecimentos. Percebemos que quando eram disponibilizadas as atividades de avaliação todos participam, porém, nos chat e fóruns, onde realmente eles poderiam ampliar seus conhecimentos, a procura foi relativamente pequena.

Faz-se aqui uma breve descrição das atividades realizadas com os alunos durante seu primeiro contato com o Wiris. O relato, além de descrever as atividades desenvolvidas, apresenta algumas percepções da equipe durante o curso e apresenta algumas observações feitas pelos alunos durante e após a realização do mesmo.

Durante o treinamento oferecido sobre o Wiris percebeu-se que os alunos tiveram certa facilidade em utilizá-lo. Após serem mostradas as ferramentas e aplicativos que o software possui e como são utilizados, foi sugerido como atividade, a resolução da situação apresentada a seguir, que recaía em uma equação do segundo grau, conteúdo que eles já estão habituados a resolver utilizando lápis e papel.

"Fernanda conseguiu montar um quebra-cabeça de $1.200 \mathrm{~cm}^{2}$ de área e resolveu fazer um quadro com ele. Para isso, comprou uma placa de compensado. As dimensões da placa de compensado são tais que o comprimento da placa tem $40 \mathrm{~cm}$ a mais que a largura. Sabendo que o quebra-cabeça montado ocupou toda a área da placa, informe quais são as dimensões da placa que Fernanda comprou". Depois da análise da situação e conclusão de que a solução do problema se daria pela resolução de uma equação do segundo grau, pediu-se que os alunos usassem um editor de texto comum para realizarem as operações objetivando a solução.

Os alunos iniciaram o trabalho: escreveram a equação do segundo grau no editor $\mathrm{e}$, tendo em mente a fórmula de Bhaskara, foram substituindo os valores $a, b$ e $c$ na mesma. A dificuldade em se escrever a fórmula neste editor de texto, naquele padrão utilizado comumente pelos alunos e apresentada abaixo, fez com que pouco a pouco eles fossem desistindo da digitação e chegassem à conclusão de que o trabalho seria muito árduo usando esse editor de texto.

$$
x=\frac{-b \pm \sqrt{b^{2}-4 \cdot a \cdot c}}{2 \cdot a}
$$

Pedimos então que eles realizassem o mesmo trabalho, utilizando o Wiris. Todos os alunos perceberam instantaneamente a diferença, que era a facilidade de se escrever matematicamente no Wiris Editor. Enquanto o editor comum dificultava a escrita de 
frações e expoentes, o Wiris permitia estas formatações através de apenas um clique. Apesar desta constatação evidente, os alunos mantiveram a mesma postura frente a essa nova ferramenta: resolviam as equações mentalmente ou com a ajuda de lápis e papel e usavam o software apenas para a escrita das equações, como se pode identificar nas primeiras linhas da resolução feita por um aluno e ilustrada na figura 2.

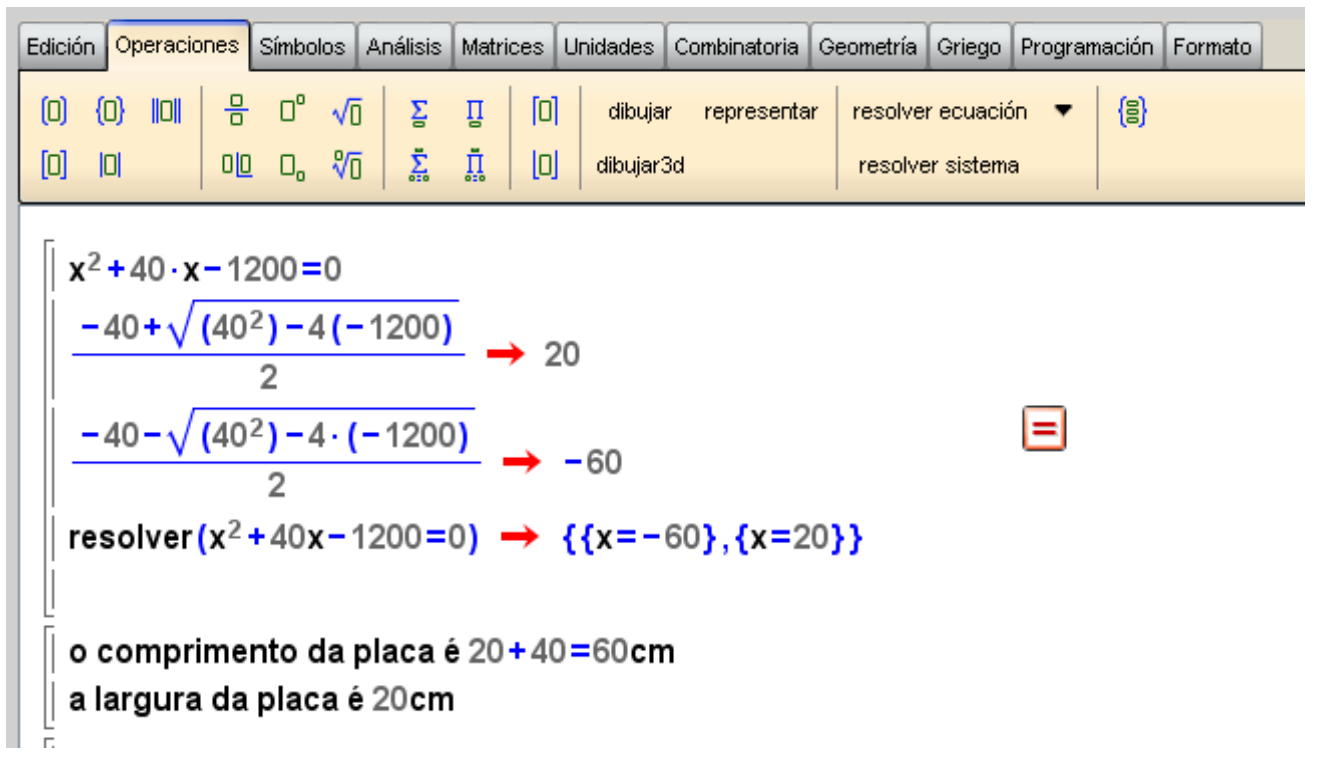

Figura 2 - Resolução de um aluno para a atividade proposta no Wiris

Percebemos nas três primeiras linhas que o aluno escreveu a equação que representa a situação proposta e passou a resolvê-la da mesma forma como faria se tivesse em mãos lápis e papel, usando o Wiris apenas como uma calculadora que apresentou o resultado das duas equações por ele fornecidas. Isso mostra a falta de familiaridade dos alunos com esse tipo de ferramenta pois, apesar de termos mostrado que ela facilitaria o trabalho, tanto na edição quanto na resolução, isso não estava acontecendo já que os alunos estavam resolvendo da mesma forma que em seus cadernos. Quando mostramos aos alunos que eles não precisavam ficar fazendo as contas, mas que tinham somente que digitar a equação e clicar em "=" que apareceriam as soluções é que de fato eles perceberam a ajuda que um programa como esse pode oferecer, como podemos observar na quarta linha de texto da figura 2.

A realização desta experiência, na qual o aluno deveria desenvolver o mesmo trabalho com e sem o uso do software Wiris, permitiu observar a reação do aluno frente a problemas a serem resolvidos. Observou-se a existência de uma postura firme em utilizar a forma tradicional de resolver a situação, mesmo havendo um software disponível que facilitaria este tipo de trabalho.

Depois da realização desta atividade, nos valendo do fato do Wiris possibilitar a utilização de recursos de geometria onde é possível criar representações de figuras tanto planas quanto sólidas, desenvolvemos a segunda atividade que foi gerar por meio do Wiris cinco sólidos geométricos específicos: tetraedro, hexaedro, octaedro, dodecaedro e icosaedro.

Para isso, os alunos precisavam apenas clicar sobre o nome do sólido desejado, fornecer ao software a medida da aresta do mesmo e clicar em "=" podendo fazer sua 
visualização em 3D. Na figura 3 o aluno clicou no dodecaedro e forneceu o número 7 , que é o tamanho da aresta do sólido construído pelo Wiris e que os alunos poderiam movimentar, girar, aumentar ou reduzir de tamanho através das setas que aparecem na parte inferior da janela ao lado esquerdo do sólido . Os alunos analisaram cada um dos sólidos e preencheram então uma tabela que solicitava o número de arestas, vértices e faces dos sólidos por eles construídos e manipulados. Após terem obtido essas informações para os primeiros sólidos construídos, os alunos perceberam a dificuldade em determinar esses dados nos sólidos que tinham um número maior de faces, como por exemplo o sólido icosaedro que possui 20 faces. Pedimos então, que eles observassem a relação que existia entre os dados já obtidos e eles conseguiram perceber, com facilidade, a existência de uma relação, a Relação de Euler, que depois de ser apresentada aos alunos foi usada para o término da atividade completando o restante da tabela. A Relação de Euler estabelece que, para todo poliedro convexo $\operatorname{com} A$ arestas, $V$ vértices e $F$ faces, vale a relação: $\mathrm{V}-\mathrm{A}+\mathrm{F}=2$.

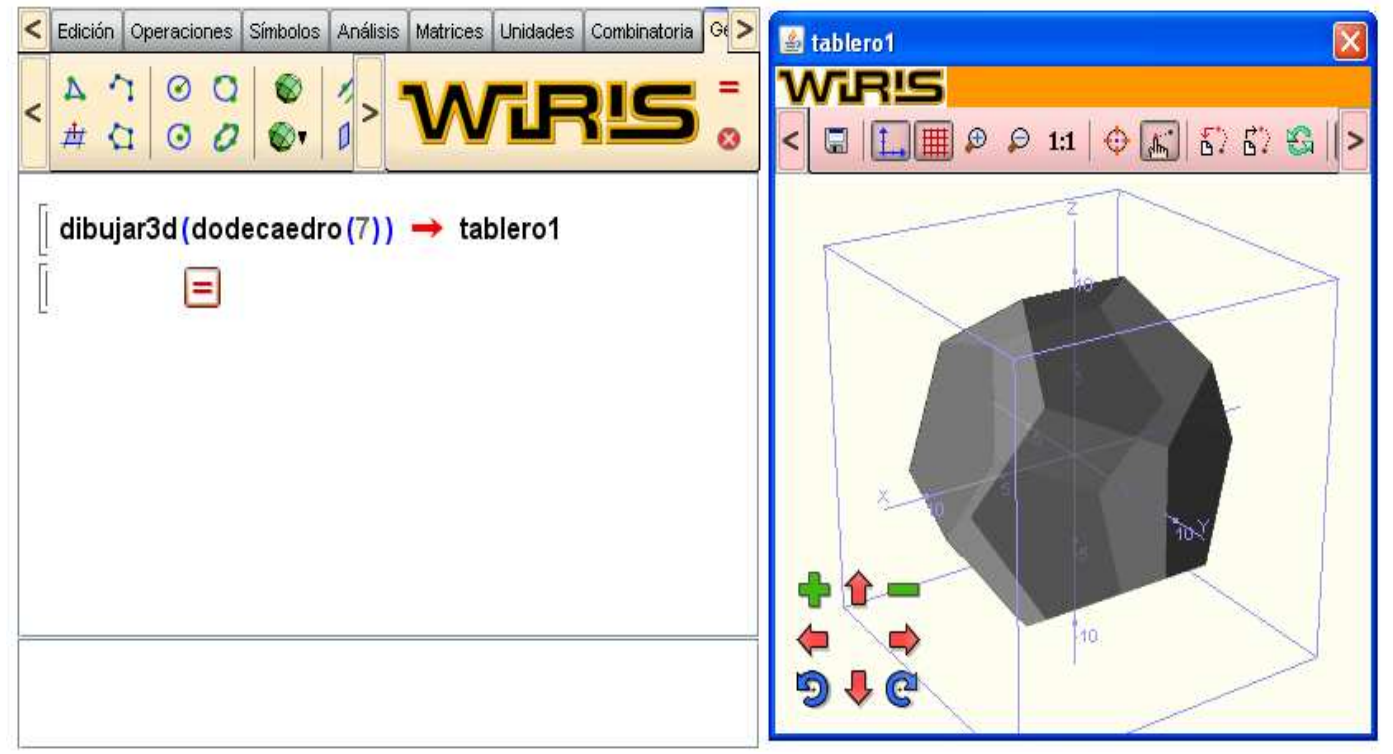

Figura 3 - Construção de sólidos geométricos no Wiris

Após o desenvolvimento dessas atividades disponibilizamos aos alunos um questionário referente ao Wiris no qual os alunos afirmaram que não conheciam o aplicativo e que o mesmo é muito mais rápido e prático em o comparando com o equivalente trabalho manual, facilitando assim o aprendizado. Afirmaram gostar do fato de poderem verificar se a resolução do exercício está correta e alguns afirmaram ainda que vão continuar usando essa ferramenta para resolver os exercícios propostos pelos professores na sala de aula e em seus estudos visando o vestibular. Alguns escreveram sobre a importância de se poder usar esse software instalado em casa sem que o computador precisasse estar conectado à internet e ainda sobre a melhoria que passariam a sentir se esse ou outro software com essas características fosse usado no dia-a-dia das salas de aula pelos professores para que houvesse uma melhor visualização dos conteúdos por parte dos alunos.

Quanto à parte de geometria foi questionado o que eles puderam observar no Wiris que utilizando a lousa ou um livro não seria possível. Todos afirmaram que a manipulação das construções geométricas (realizadas quando eles giravam, 
aumentavam, reduziam e comparavam as figuras) é o fato que mais ajuda na compreensão a determinação das características das mesmas.

Os alunos deixaram transparecer, de forma bastante clara, seu gosto pelo uso do Wiris. Porém percebemos, com a mesma clareza, que apesar de saberem as funcionalidades do programa eles acabam, infere-se que por costume, ou pela ciência da não disponibilidade do mesmo para atividades escolares cotidianas, a não usar toda a sua potencialidade no desenvolvimento das atividades.

Após o treinamento oferecido disponibilizamos o Wiris como ferramenta de edição de texto para todas as atividades propostas no projeto USFMat e ainda para ser usado nos chats e fóruns com o intuito de que os alunos redigissem com eficiência e clareza, lições e tarefas disponibilizadas no Moodle e que os professores e alunos pudessem tirar dúvidas pelos chats ou pelo fórum, redigindo fórmulas e cálculos, facilitando assim as explicações e a compreensão do conteúdo.

\section{Conclusões}

O desenvolvimento de estudos de caso envolvendo atividades diretamente relacionadas com alunos, a exemplo deste, realizado através do projeto USFMat, é sempre importante e rico no sentido de que permite uma visão ampliada de como os alunos constroem sua maneira própria de lidar com o problema, quais são suas dificuldades e suas opiniões. No entanto, este trabalho consiste no relato de ações realizadas visando levantar o maior número possível de informações, dados e fatos que pudessem servir de referência e que nos ajudassem a compreender, e não explicar, um pouco mais sobre as ações, comportamentos e estratégias de aprendizagem dos alunos.

As opções para uso de softwares no ensino da matemática são muitas, normalmente gratuitas e com variados objetivos, conteúdos e níveis. Entretanto, apesar do entendimento de sua importância e da popularização dos computadores nas escolas, percebemos de maneira clara que o uso deste tipo de ferramenta, a exemplo do Wiris, nem sempre é de conhecimento de alunos e professores, estando ausente no dia-a-dia das atividades escolares embora se observe o número cada vez maior de tecnologias e softwares que vêm sendo desenvolvidos, especialmente para a área educacional.

Os alunos deixaram transparecer durante a realização do trabalho e também depois de sua conclusão, através do preenchimento de um questionário de avaliação, o quanto o fato de poder conferir as respostas e visualizar graficamente resultados é favorável no aprendizado da matemática, o que corrobora com a idéia discutida no início do texto de que as tecnologias contribuem para o desenvolvimento de uma aprendizagem significativa, prazerosa e eficaz, capaz de despertar no educando, o interesse e a motivação pela busca do conhecimento.

O projeto USFMat teve duração de 13 meses, tendo suas atividades findadas em dezembro de 2010. Durante sua realização foram ofertadas 54 horas de aula presencial de informática e 66 horas de aula presencial de matemática que aconteceram aos sábados na escola Dr. João Ferreira Neves, em Catanduvas, e na Unioeste, em Cascavel. Foram ofertadas ainda 396 horas de monitorias em chats via Moodle que aconteciam em seis horários pré-definidos de segunda a sexta-feira. Como apoio às aulas, foram elaboradas 14 apostilas totalizando 364 páginas, sendo que destas 175 são de conteúdos matemáticos e 189 são de conteúdos de informática. A equipe deslocou-se até a cidade de Catanduvas por 18 vezes para ofertar cursos na referida escola e os alunos estiveram 
por quatro vezes na Unioeste, participando de cursos.

Cabe dizer que os alunos tiveram apenas cerca de 7 meses de contato com o Moodle e o software Wiris, período considerado curto para avaliar com mais precisão, os efeitos do uso dos mesmos no dia a dia dos alunos, ou mesmo, simplesmente para identificar se foi possível, através dessas ações, conscientizá-los com relação à potencialidade do uso das TICs, não apenas para fins educacionais, mas para a vida.

\section{Agradecimento}

Os autores agradecem o financiamento recebido da Fundação Araucária e do Governo do Estado do Paraná/SETI.

\section{Referências Bibliográficas}

BELLONI, M. L. Educação a distância mais aprendizagem aberta. 21 Reunião Anual da ANPED. 1998

BOVO, V. G. O uso do computador na educação de jovens e adultos. Rev. PEC, Curitiba, Vol. 2. No. 1. Julho. 2001. 105-112p.

DRAGMATH. Acesso em 12/08/2010 <http://www.dragmath.bham.ac.uk/>.

GONÇALVES, J.P., SALVADOR, J.A. Educação a distância e o moodle: Novas formas de ensinar e de aprender matemática. UFSCar. 10p, 2002.

IPARDES. Diagnóstico Socioeconômico do Território do Cantuquiriguaçu. 145 pg. Curitiba, 2007. Acesso em: 13/09/2010. Disponível em: <http://www.ipardes.gov.br/biblioteca/docs/territorio_cantuquiriguacu.pdf $>$.

MARQUES D.,Eixarch R.,Casanellas G., R., Martinez B.. WIRIS OM Tools: a Semantic Formula Editor. Maths for More S.L. Rambla de Prat 21 1r 1a 08012, Barcelona, Spain, 2006.

MOODLE. Open-source community-based tools for learning. Acesso em 16/08/2010 <http://moodle.org/>.

S. XAMBÓ, R. EIXARCH, D. MARQUES. WIRIS: An Internet platform for the teaching and learning of mathematics in large educational communities. Departament de Matemàtica Aplicada II i Facultat de Matemàtiques i Estadística; Universitat Politècnica de Catalunya Maths for More. S.L. Barcelona. 2002.

TORTOSA, G. S. Didática del Álgebra. Buenos Aires, Libros del Zorzal, 2004.

USF. Universidade Sem Fronteiras. Acesso em 07/12/2010. Disponível em: 〈http://www.usf.pr.gov.br/modules/conteudo/conteudo.php?conteudo=11 > .

VALENTE. J. A. (org). Computadores e conhecimento: repensando a educação. Campinas: UNICAMP, 1993.

Diferentes usos do computador na educação. s/d. Acesso em 13/09/2010. Disponível em: http://edutec.net/Textos/Alia/PROINFO/prf_txtie02.htm

Informática Aplicada à Educação: Programas Educativos para

o ensino fundamental. Acesso em: 29/04/2011. Disponível em: http://www.webartigos.com/articles/9664/1/Informatica-Aplicada-A-EducacaoProgramas-Educativos-Para-O-Ensino-Fundamental/pagina1.html\#ixzz1MvZMGKZq 